\title{
PERCEPÇÃO SOBRE O LEGADO DOS MEGAEVENTOS ESPORTIVOS NO BRASIL: O CASO DA COPA DO MUNDO FIFA 2014 E OS JOGOS OLÍMPICOS RIO 2016
}

\author{
DR. CARLOS HENRIQUE DE VASCONCELLOS RIBEIRO \\ Programa de Pós-graduação em Educação Física, \\ Universidade Gama Filho (UGF/RJ) \\ (Rio de Janeiro - Rio de Janeiro - Brasil) \\ E-mail: c.henriqueribeiro@ig.com.br
}

\section{DR. ANTONIO JORGE GONÇALVES SOARES \\ Programa de Pós-graduação em Educação, Faculdade de Educação, \\ Universidade Federal do Rio de Janeiro \\ (Rio de Janeiro - Rio de Janeiro - Brasil) \\ E-mail: ajsoares@globo.com}

\author{
DR. LAMARTINE PEREIRA DACOSTA \\ Programa de Pós-graduação em Educação Física, \\ Universidade Gama Filho (UGF/RJ) \\ (Rio de Janeiro - Rio de Janeiro - Brasil) \\ E-mail: lamartine@terra.com.br
}

\begin{abstract}
RESUMO
O Brasil irá sediar dois dos mais importantes eventos esportivos mundiais, a Copa do Mundo FIFA 2014 e os Jogos Olímpicos RIO 20 I6. O objetivo desta pesquisa é verificar a percepção dos profissionais de educação física da cidade do Rio de Janeiro sobre o legado que estes megaeventos podem trazer para suas vidas tanto em termos de desenvolvimento profissional quanto em questões relacionadas ao seu cotidiano. Em nossa discussão de resultados levantamos tópicos sobre os impactos e expectativas sobre os megaeventos no mercado de trabalho para estes professores, valorização profissional, prática e aumento do interesse esportivo, legado social e suas sugestôes para o sucesso destes eventos.
\end{abstract}

PALAVRAS-CHAVE: Legados; Copa do Mundo FIFA 20 I4; Jogos Olímpicos Rio 20 l 6; percepção. 
O Brasil irá sediar nos próximos anos dois dos mais importantes eventos esportivos mundiais, a Copa do Mundo FIFA 2012 e os Jogos Olímpicos RIO 2016. Em termos gerais, nossa participação no cenário esportivo mundial tem se destacado mais como fornecedor de mão-de-obra do que com resultados expressivos em competições internacionais, excetuando-se, é claro, esportes como o futebol, futsal e o voleibol (RIBEIRO; DIMEO, 2009). De uma maneira geral, nossa sociedade ainda se encontra em um estágio de desenvolvimento econômico e social muito aquém do necessário para oferecer condições de vida digna para toda população. Além disso, teremos pela frente a tarefa de nos próximos anos construir e ampliar equipamentos esportivos, investindo recursos robustos em infraestrutura.

É recorrente o discurso entre autoridades políticas, esportivas e mídia em geral, que estes megaeventos podem ser potencializadores de mudanças significativas tanto em termos desta infraestrutura (melhoria na rede de transportes públicos e desenvolvimento da rede de turismo, por exemplo) quanto em relação ao reconhecimento mundial sobre a capacidade de nosso país organizar tais megaeventos em um tempo relativamente curto. Desta forma, as melhorias para a população podem ser de duas naturezas, aquelas chamadas de tangíveis, como por exemplo, a melhoria do sistema de transporte, e até mesmo aquelas consideradas intangíveis, tais como a melhoria da autoestima dos moradores das cidades envolvidas (POYNTER, 2008).

A expressão "uma grande oportunidade" tem sido recorrente e propagada pelos meios de comunicação para definir a passagem destes dois próximos megaeventos, realçando que significativas intervenções urbanas podem ser realizadas e que a sociedade tende a ter benefícios com isto.' Neste sentido, a palavra legado utilizada neste texto tem um sentido positivo. Compreendemos que, apesar de todos os riscos financeiros que poderemos ter que arcar como contribuintes nos próximos anos e até mesmo décadas, as mobilizações políticas para que uma série de intervenções seja realizada tende a impactar positivamente na vida dos moradores das cidades-sede dos jogos e, no caso específico da cidade do Rio de Janeiro, em diversas alterações no mobiliário urbano. Tais como a metáfora da pedra lançada no lago e que as ondas reverberam por diversos espaços, acreditamos que os impactos serão em maior ou menor proporção no cotidiano da população, tendendo a alterar, por exemplo, a mobilidade urbana.

I. Foram analisados nesta pesquisa os jornais $O$ Globo, Lance e a Revista Veja no período de setembro de 2009 a abril de 2010. 
Apesar disso, ainda existem muitos questionamentos, inclusive dos órgãos públicos de fiscalização, sobre a utilização de tais recursos, sobre as formas em que todos os equipamentos esportivos foram entregues à população da cidade do Rio de Janeiro e a forma que foram gastos durante a realização dos Jogos Pan-Americanos de 2007.

Em termos acadêmicos, a produção do livro "Legados de megaeventos esportivos" (DACOSTA et al., 2008) reuniu autores que estudaram o impacto positivo que os Jogos Pan-Americanos de 2007 trouxeram ao Brasil e mais especificamente à cidade do Rio de Janeiro. Estes estudos situam-se no arcabouço teórico conhecido como Estudos Olímpicos (EO).

Além deste livro, é preciso ressaltar o relevante material de pesquisa intitulado "Dossiê 2007-2016 - a década dos megaeventos esportivos no Brasil" da Revista Motrivivência de 2009. Este material traz, em linhas gerais, uma crítica aos investimentos a serem gastos na realização destes megaeventos e a opção equivocada do governo brasileiro em priorizar o direcionamento destes gastos em áreas menos importantes à população, segundo a maioria de seus autores.

Em termos profissionais, quando grandes eventos esportivos acontecem (principalmente aqueles com cobertura midiática), muitos professores de educação física acabam por atuar como dirigentes, treinadores, atletas, árbitros, voluntários, entre outras funções de apoio, além de ver sua área de atuação sendo propagada, comentada e discutida por especialistas e pelo público em geral, disseminando uma cultura esportiva alinhavada por estes megaeventos.

Para o conceito de cultura esportiva nos apoiamos nos estudos de Pires (2000, p. 15), que a define como

\footnotetext{
"o conjunto de ações, valores e compreensões que representam o modo predominante de ser/estar na sociedade globalizada, em relação ao seu âmbito esportivo, cujos significados são simbolicamente incorporados através, principalmente, da mediação feita pela indústria da comunicação de massa".
}

Apesar de todas essas possibilidades de trabalho para a educação física, avaliamos que nem todos os profissionais desta área percebem estas oportunidades, principalmente aqueles que estão atuando no espaço público. É preciso avaliar as consequências destas políticas públicas para os profissionais que vivem o dia a dia esportivo no âmbito da intervenção pedagógica, visto que o sistema político econômico tende a privilegiar poucos em detrimento de muitos.

Mas qual é a percepção sobre o legado destes dois próximos megaeventos esportivos para os profissionais de educação física que atuam no espaço público dentro da cidade do Rio de Janeiro? 
objetivo desta pesquisa é analisar como os profissionais de educação física que atuam em espaços públicos compreendem o impacto dos megaeventos esportivos na cidade do Rio de Janeiro.

Estudar como estes megaeventos podem trazer para suas vidas, tanto em termos de desenvolvimento profissional quanto em questões relacionadas ao seu cotidiano, ao exercício de sua cidadania social. Avaliamos seus posicionamentos nas questões relacionadas ao desenvolvimento de uma cultura esportiva para a população, as oportunidades de trabalho e o legado social que estes megaeventos podem vir a deixar nesta cidade.

Para efeito de definição, compreendemos um megaevento esportivo como uma competição que, para ser realizada, necessita de grande aporte financeiro, logístico e humano. Apresenta também grande poder de atração de mídia e é realizada regularmente a cada período de 4 anos. Normalmente são sedes destes megaeventos países economicamente desenvolvidos e que apresentam estabilidade política para que as construções nas instalações perpassem a alternância de poder e tragam a garantia de realização destes megaeventos (DACOSTA, 2008).

A partir de toda expectativa criada na realização destes dois megaeventos esportivos, principalmente com a grande influência dos meios de comunicação para a sua divulgação (GURGEL, 2008), nos deteremos na percepção de profissionais de educação formados e que atuam sob égide do espaço público, quer no âmbito do ensino regular e formal, quer seja em projetos esportivos sociais. Depois dos Jogos Pan-Americanos Rio 2007, acreditamos ser necessário compreender como uma parcela específica de profissionais que lidam com o esporte em seu cotidiano percebem estes dois megaeventos.

\section{REFERENCIAL TEÓRICO}

Como escrevemos anteriormente, a obra "Legados de megaeventos esportivos" (DACOSTA et al., 2008) apresenta uma série de pesquisas pertencentes aos mais diversos tipos de profissionais que procuraram, sobretudo, estudar o impacto da passagem dos Jogos Pan-Americanos no Brasil e, em específico, para a população da cidade do Rio de Janeiro, durante o ano de 2007. A preocupação quanto ao que é considerado legado em megaeventos se destaca de forma consistente, principalmente sobre a participação do poder público com grandes somas de recursos financeiros e da justificativa da utilização desta para a melhoria da qualidade de vida da população (DACOSTA et al., 2008).

Porém, esta é apenas a terceira obra focada em estudos sobre legados de megaeventos realizados no Brasil (DACOSTA; MIRAGAYA, 2008, p. 38). Mostra-se 
com isso a necessidade de mais estudos nesta área, sobretudo porque, em última instância, é preciso dar visibilidade na qualidade da gestão dos recursos públicos e se estes retornam para todos.

Em relação aos tipos de legado, Gnecco (2008, p. 268) os classifica como: a) legado esportivo; b) legado de transporte; c) legado de tráfego; d) legado de telecomunicações; e) legado social; f) legado de segurança; g) legado de habitação; h) legado de conhecimentos; i) legado de imagem; j) legado de emoções; k) legado de cultura.

Em nosso estudo queremos compreender como estes tipos de legados são percebidos pelos professores de educação física e se, de maneira geral, eles sentem-se incluídos neste processo dentro da cidade do Rio de Janeiro, local onde trabalham e vivem grande parte de suas vidas.

Para Raeder (2008), o conceito de legado é definido como

\footnotetext{
"um conjunto de bens materiais e imateriais que se conformam como permanências sócio-espaciais no tecido urbano decorrentes das ações compreendidas por conta da implementação de um megaevento." (pág. 206)
}

Os bens materiais são as estruturas esportivas e as estruturas de transporte, por exemplo. Já os bens imateriais estão ligados ao capital simbólico decorrente da realização dos jogos, como por exemplo, a percepção da população sobre a própria cidade e a propagação da imagem da cidade para outras partes do mundo (RAEDER, 2008).

Antes, durante e depois dos Jogos Pan-Americanos Rio 2007 várias pesquisas foram elaboradas, principalmente com o objetivo de avaliar a percepção positiva de grupos específicos envolvidos direta ou indiretamente na realização deste evento (CARVALHO; MELO; DACOSTA, 2008; FERREIRA; COSTA, 2008; HAAS et al., 2008; MATARUNA, 2008; MOURÃO et al., 2008; SCHÜLER et al., 2008; SOUSA; SILVA, 2008).

Do legado político ao legado sobre o voluntariado, de estudantes a especialistas, estes estudos tiveram como preocupação mostrar as correlações entre a passagem dos jogos no Rio de Janeiro e o impacto na vida de profissionais que estudam e/ou trabalham com o esporte. Mas parece existir uma premissa teórica nas pesquisas realizadas: a passagem dos jogos é considerada legado. Quer seja pelos bens materiais ou imateriais, a discussão feita pelos pesquisadores ressalta que houve um ganho e este precisa ser avaliado nas dimensões da inclusão social, multiculturalismo, sustentabilidade, turismo e voluntariado, entre outras temáticas.

Além desta obra, incluímos também o material realizado pela Revista Motrivivência (Ano XXI, n³2/33, 2009), em que diversos pesquisadores se debruçam sobre esta temática de forma a 
(...) abordar, de forma crítica e multidisciplinar, a problemática dos megaeventos esportivos e suas repercussões políticas, econômicas, com isso, subsidiar reflexões sobre as políticas públicas no campo do trabalho, educação, lazer, segurança, mobilidade. (p. 09-10)

Tal obra se faz importante como contraponto teórico-metodológico aos estudos que tendem a superestimar a presença econômica e política destes megaeventos de passagem em terras tupiniquins.

Discutiremos nas próximas páginas se os professores de educação física consideram que os megaeventos a serem realizados serão percebidos como legados, visto que no momento em que este texto está sendo escrito estamos a cerca de 3 anos da realização da Copa do Mundo FIFA 2014 e a 5 anos das Olimpíadas Rio 2016.

\section{MATERIAIS E MÉTODOS}

Esta pesquisa tem o formato de survey e apresenta uma amostra de conveniência. Apesar de não ter validade estatística, contribui para análises qualitativas e pode ajudar em futuras tomadas de decisões, principalmente no que se refere às populações pesquisadas (THOMAS; NELSON; SILVERMAN, 2007).

Utilizamos como coleta de dados um questionário validado por três especialistas da área (três doutores em educação física com atuação na área de humanidades). A maioria de suas questões eram fechadas e apenas uma era aberta. Deixamos esta última neste formato para que o respondente fizesse suas observações finais sobre algo que gostaria de comentar, criticar, enfim, contribuir mais caso desejasse. Para Mourão et al (2008, p. 285),

\footnotetext{
"os estudos de percepção centram, de forma geral, seus estudos sobre a relação sujeito objeto, entendendo que este sujeito através de sua atividade e relação com o objeto-mundo, constrói tanto o mundo quanto a si próprio.
}

Responderam à pesquisa 60 profissionais de educação física que atuam no âmbito do ensino regular e em projetos esportivos sociais mantidos pelo poder público na cidade do Rio de Janeiro nas três esferas governamentais. Entre eles, 37 homens e 23 mulheres com faixa etária entre 32 a 56 anos. Todos mantém pelo menos mais um vínculo empregatício na área escolar de educação física, quer seja em escolas privadas ou com outras matrículas junto a outras redes públicas de ensino. Apenas 9 profissionais mantém três vínculos, sendo o terceiro ligado à área de fitness (academias de ginástica e musculação). Todos estes professores são profissionais contratados por meio de concurso público. Foram visitadas 5 unidades distintas, próximas a uma mesma região administrativa da cidade carioca, conhecida como Zona da Leopoldina, entre os meses de setembro de 2009 a março de 2010. 
Todos os respondentes de nossa pesquisa foram informados dos objetivos de nossa pesquisa através da leitura e posterior consentimento através de nosso Termo de Consentimento Livre e Esclarecido (TCLE). Ressaltamos, ainda, que nossos respondentes não eram obrigados a se identificar e, ainda, que priorizamos os seus horários livres (intervalo das aulas) para que pudessem preencher o questionário.

A escolha desta região da cidade se deve ao fato de o projeto esportivo social visitado concentrar um grande número de escolinhas esportivas, mantendo a tradição de participação em diversos campeonatos municipais e estaduais. Foram ainda visitadas quatro unidades regulares de ensino. A escolha destas quatro unidades se deu porque estas estão próximas umas das outras, fazendo com que o projeto esportivo social visitado tenha uma grande concentração de alunos provenientes destas unidades escolares.

Os questionários eram entregues após uma pequena conversa com os respondentes. Nesta conversa fazíamos questão de ressaltar da não necessidade de identificação e também situávamos os pesquisados sobre a temática abordada. Dividimos nossa análise em seis temáticas, pois foi possível reunir algumas perguntas que eram suscetíveis de serem analisadas juntas.

Escolhemos intencionalmente esta amostra, pois também nos incluímos neste mesmo grupo de profissionais. Tal fato faz com que tenhamos um cotidiano muito próximo, e rotineiramente enfrentamos a missão de ensinar a disciplina educação física na escola. Fazemos parte, portanto, de uma mesma comunidade discursiva, pois partilhamos de um mesmo vocabulário comum, contingente e fruto de nossas relações sociais (FOUCAULT, 1996). Além disso, percebemos que tem sido frequente a menção dos dois megaeventos, tanto em reuniões pedagógicas (conselhos de classe, centro de estudos, por exemplo) quanto nas conversas do dia a dia, do bate-papo da hora do café. Porém, compreendemos que isto acaba por trazer um discurso de desconfiança e, porque não dizer, animosidade entre os professores.

Além disso, não raro percebemos que os alunos comentam sobre estes dois megaeventos e, quando estão no espaço escolar, acabam por fazer trabalhos relacionados à Copa do Mundo e às Olimpíadas nas avaliações teóricas da disciplina educação física.

Estudar o impacto destes dois eventos é, neste momento, estudar um pouco este grupo que parece ficar constantemente à margem das decisões políticas, fazendo um corte e análise da realidade dos espaços públicos esportivos.

\section{DISCUSSÃO}

Os resultados foram tabulados e colocados na forma de gráfico, para melhor entendimento. 
- O IMPACTO DOS MEGAEVENTOS NAS CONDIÇÕES DE TRABALHO

Em um primeiro momento queríamos compreender a percepção dos respondentes sobre o impacto dos megaeventos em suas condições de trabalho. $\bigcirc$ gráfico | apresenta o resultado.

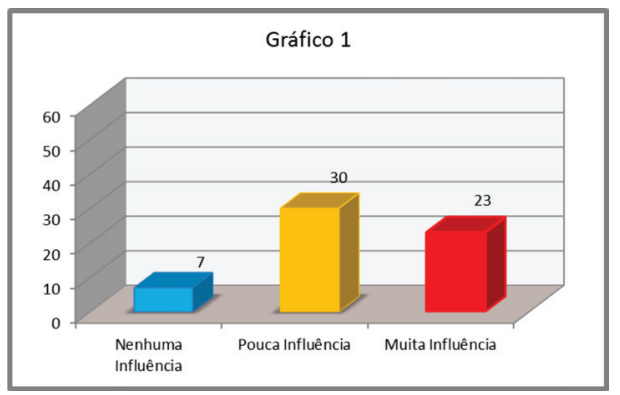

Quando perguntados sobre sua própria condição de trabalho, 50\% dos professores (30) não consideram que sua condição de trabalho irá mudar muito. Se somarmos aos 7 respondentes que acreditam que não haverá influência alguma na passagem destes megaeventos, temos mais de 60\% (37) de professores que percebem a realização da Copa do Mundo e das Olimpíadas como incapazes de alterar positivamente suas condições de trabalho. De forma oposta, quase 40\% (23) dos entrevistados acredita que haverá mudanças significativas. Acreditamos que para aqueles que estão no serviço público, as políticas de investimento estão sob forte influência sazonal-eleitoral. Inferimos que tal fato gera uma compreensão em muitos momentos cética em relação ao ambiente de trabalho, pois normalmente a realização de obras (tais como a cobertura de quadra), o aumento salarial e a compra de materiais esportivos são melhorias esporádicas e dependem de uma complexa ação política das esferas federal, estadual e municipal. A relação impacto/legado não é vista pelos docentes como algo que possa trazer melhorias, até porque as políticas governamentais ainda são incipientes para que se faça da escola um espaço para promoção adequado para as práticas das atividades físicas e do esporte.

Os estudos sobre percepção sofrem grande relação com o período em que são realizados (MOURÃO et al., 2008; CAVALLI; CAVALLI; MESQUITA, 2008; SOUSA, 2008). Neste sentido, acreditamos que o resultado está relacionado à passagem dos jogos Pan-Americanos de 2007 que, em termos gerais, pouco alterou a realidade das condições de trabalho destes profissionais e ainda não foi substituída por uma nova percepção dos novos megaeventos.

Como a educação física praticada em esferas públicas não está distante da realidade de outras esferas de prestação serviços, compreendemos que o relativo 
ceticismo se deve a anos de inoperância governamental, independente do partido político e do governante que está ocupando o cargo máximo de nossa nação. Além disso, é impreciso o impacto econômico, pairando dúvidas entre o que é esperado (e toda excitação midiática gerada em torno destes megaeventos) e o real desenvolvimento a ser distribuído entre as diversas camadas da população, como assinalou Proni (2009).

\section{- EXPECTATIVAS SOBRE OPORTUNIDADE DE TRABALHO}

A segunda pergunta se aproximava da primeira, na medida em que perguntava aos respondentes o nível de expectativa sobre as oportunidades de trabalho que podem vir a surgir para os profissionais de educação física. $\bigcirc$ gráfico 2 apresenta o resultado.

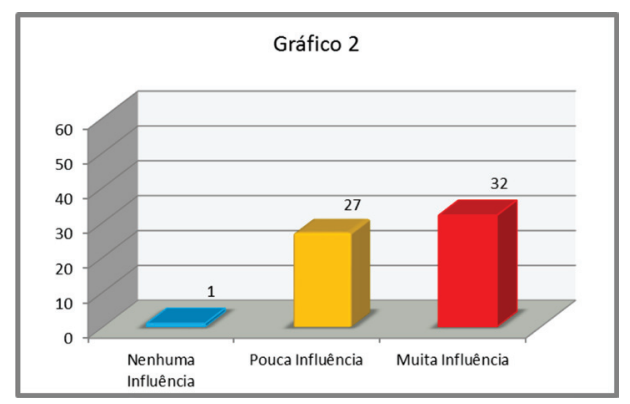

As respostas revelam algo significativo. Quando perguntados sobre as perspectivas de trabalho, as respostas foram mais positivas. Quase 55\% (32) dos respondentes acreditam que estes megaeventos terão muita influência no mercado de trabalho da educação física. Acreditamos que as respostas revelam que os professores que atuam nestes espaços públicos não se sentem incluídos nas futuras competições, pelo menos em suas áreas de trabalho.

Observamos que na discussão em torno destes eventos, o que tem sido ressaltado são as construções de estádios, arenas, linhas de metrô, reforma dos aeroportos, entre outros. Todavia, o legado parece não incluir o pequeno mundo do esporte escolar, ou seja, os recursos investidos ou a criação de empregos não inclui os profissionais que atuam com a educação esportiva na educação básica. De fato, a atividade econômica crescente para as localidades que sediam estes eventos é identificada de longo prazo, e não necessariamente inclui os profissionais de educação física que trabalham com o esporte na sua dimensão escolar.

Quer pese a diferença entre esporte de rendimento e esporte praticado na escola, ainda não há uma correlação em que se possa construir um suporte 
teórico-metodológico que sustente as iniciativas de promover um esporte de cunho educacional que ultrapasse as barreiras conceituais dicotômicas entre o esporte da escola e o esporte na escola. Lovisolo e Lucero (2006) encontraram forte correlação entre o esporte competitivo praticado no ambiente escolar e seu impacto na formação das identidades de alunos e alunas de um mesmo colégio. Neste sentido, uma forma de promover melhorias de trabalho para estes professores de educação física é via política escolar, aumentando as competições escolares, oferecendo horas-extra para pagamento de formação de equipes neste ambiente, criando um sistema de transportes para o deslocamento dos alunos, entre outras medidas.

\section{- VALORIZAÇÃO PROFISSIONAL}

Na pergunta 3 gostaríamos de saber se os profissionais de educação física consideram que estes megaeventos irão ter impacto na valorização profissional. Após responderem sobre condições de trabalho e aumento de oportunidades de trabalho de forma geral, nos pareceu importante saber como os respondentes percebem a valorização da educação física. Abaixo mostramos o resultado:

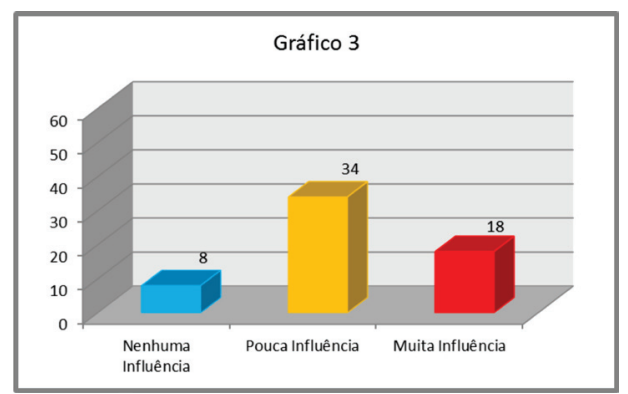

Sabemos que a percepção sobre a valorização profissional é um assunto complexo. Ela envolve normalmente questões gerais, tais como as condições salariais, o status social frente às outras profissões, os equipamentos adequados para o exercício da profissão e a carga horária de trabalho semanal.

Em nossa pesquisa, identificamos que nosso resultado se aproxima dos encontrados por Carvalho, Melo e DaCosta (2008), que demonstrou não existir alteração significativa sobre o status profissional e a realização de um megaevento esportivo. Esse estudo foi realizado para captar o impacto dos jogos Pan-Americanos Rio 2007 para profissionais de educação física. $\bigcirc$ estudo em tela aponta que mais de 55\% (34) dos professores de educação física considera que a realização destes megaeventos terá pouca influência na valorização profissional. Inferimos que neste momento os profissionais não percebem esta valorização até porque, em termos 
governamentais, pouco foi feito até o momento. E, provavelmente, a valorização profissional esteja relacionada àqueles que estão por hora ocupando cargos de dirigentes, técnicos e atletas destas futuras competições. As novas oportunidades de trabalho especializado dentro da educação física parecem não ter atingido este grupo até o momento. Ou seja, esporte profissional e esporte educacional parecem não ser vistos como complementares na percepção do grupo estudado.

Betti (2009) sugere que há um inversionalidade nas políticas públicas sobre o desenvolvimento de uma cultura esportiva, sobretudo no âmbito escolar, forçando que a escola, de uma hora para outra, seja a responsável pelo surgimento de novos talentos esportivos, sem que com isso existam condições humanas e materiais para tal. Esta inversionalidade acaba por gerar frustrações, pois o fracasso com tais expectativas é eminente e injusto para com estes profissionais.

\section{- PRÁTICA E AUMENTO DO INTERESSE ESPORTIVO}

As perguntas 4 e 5 estavam correlacionadas para que pudéssemos avaliar a percepção entre o aumento da prática esportiva para a população em geral e o consequente aumento do interesse sobre esportes.

Os gráficos 4 e 5 apresentam os seguintes resultados.
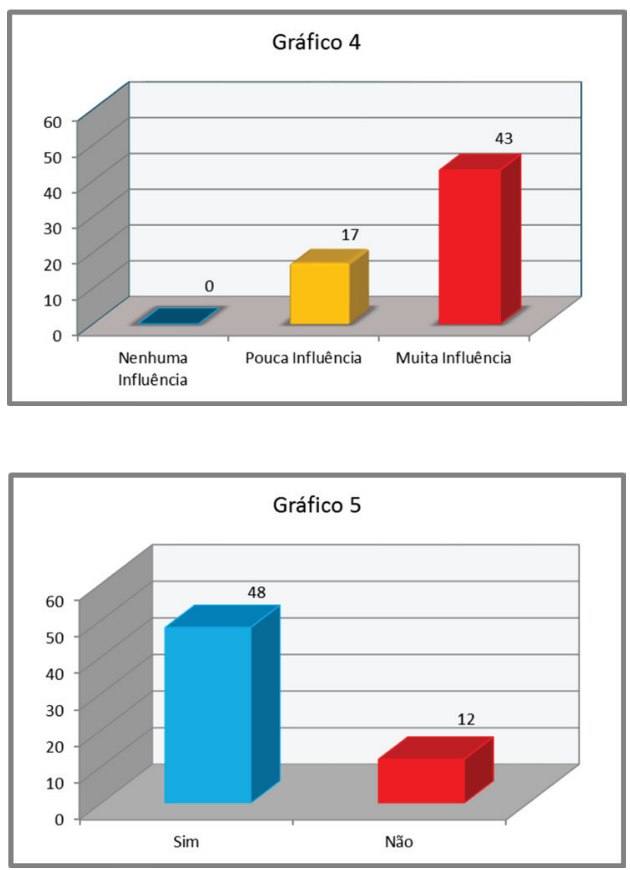
Quando perguntados sobre aumento da prática de esportes, mais de 70\% (43) dos respondentes acredita em muita influência (Gráfico 4). Na mesma linha de questionamento, $80 \%$ (48) dos professores de educação física acreditam em aumento do interesse esportivo para a população (Gráfico 5).

É alto o nível de expectativa em relação ao aumento da prática esportiva na população, bem como o interesse sobre esportes. $\bigcirc$ resultado destas perguntas se assemelham ao encontrado por Mourão et al. (2008) no que tange à expectativa de um incremento positivo sobre a adesão da população na prática dos exercícios físicos e de esportes de lazer devido à aproximação destes megaeventos. Resultados próximos foram encontrados em outros dois estudos sobre percepção, mas com populações distintas de nossa pesquisa (CAVALLI; CAVALLI; MESQUITA, 2008; SOUSA, 2008). Todavia, devemos destacar que nenhum estudo demonstrou a relação causal entre os megaeventos e o aumento da prática de exercícios físicos ou adesão à prática esportiva.

O que está em questão é que os professores acreditam em boas perspectivas de adesão ao esporte, na medida em que estes eventos se aproximarem temporariamente. Inferimos que os meios de comunicação são parte importante deste processo, fazendo com que seja possível uma propagação das culturas esportivas (PIRES, 2000) em nível local, regional e nacional. Interpretamos que o sucesso esportivo, com a conquista de medalhas através da personificação positiva de um atleta esportivo, aliado a uma boa cobertura midiática, tende a colocar na pauta de discussões o desenvolvimento de culturas esportivas no Brasil, conforme o pensamento de Pires (op. cit.).

A iniciativa de divulgar os preceitos olímpicos no espaço escolar poderia deixar de ser uma iniciativa individual e isolada de poucos professores para se tornar um movimento pedagógico coletivo. Observamos que na medida em que a circulação de informações relacionadas ao esporte tende a aumentar, aproveitar-se-ia esta circulação de informações para que instalássemos no Brasil os preceitos de uma educação olímpica de longo prazo (TAVARES, 2008; TURINI; SANTOS, 2008).²

- LEGADO SOCIAL

legado social pode ser entendido como aquele que está associado à implementação de intervenções urbanísticas que visem à melhoria da qualidade de

2. Em nossa experiência como professores de educação física, não raro percebemos um incremento rápido e por vezes frugal no número de praticantes depois que determinada modalidade esportiva consegue resultados positivos em uma olimpíada ou torneio com grande destaque midiático. Como exemplo, verificamos um aumento significativo de matrículas no tênis dentro dos espaços públicos, bem como a construção de novas quadras depois do sucesso de Gustavo Kurten com suas conquistas em Roland Garros durante a década de 1990, mas passada esta "febre", logo o número de matrículas volta a ser reduzido. 
vida das populações envolvidas nas competições, tais como o acesso à moradia, saúde, segurança e transportes (GNECCO, 2008). É sobre este legado que pesam as justificativas para que o poder público invista grandes somas de recursos nas obras exigidas pelas entidades promotoras das competições, e também fonte de discussão no meio acadêmico, principalmente aqueles autores que se debruçam sobre da gestão dos recursos financeiros despendidos para tal fim (BECHARA, 2008; MAZO, 2008; PREUSS, 2008).

Sobre a influência destes megaeventos e um provável legado social, os professores tiveram a seguinte percepção:

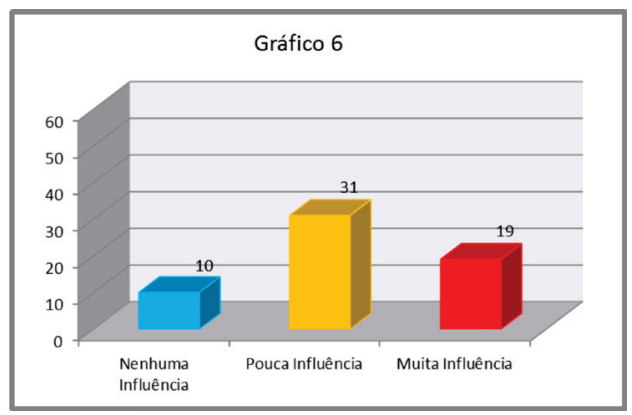

O resultado mostra que mais de $50 \%$ dos respondentes ( $3 \mathrm{I}$ ) acredita que haverá pouca melhoria das condições de vida da população. Pouco mais de 30\% (19) dos professores acredita que haverá muita influência. Essa percepção dos professores contraria aquilo que é chamado de "grande oportunidade" propagada pelos principais meios de comunicação, e o principal argumento de autoridades políticas e esportivas. A maior parte dos professores percebe que o legado a ser deixado terá pouca ou nenhuma influência no cotidiano da população. ${ }^{3}$

Além disso, os autores que avaliam os impactos, legados e sua abrangência tendem a categorizar os legados em tangíveis e intangíveis, como comentado anteriormente (POYNTER, 2008). Para que seja possível alcançar a percepção dos respondentes sobre o legado tangível (infraestrutura do megaevento), é obrigatório que as intervenções urbanísticas sejam iniciadas e a população destes locais comece a usufruir destas realizações e, posteriormente, os legados intangíveis possam ser alcançados.

3. O presidente do $\mathrm{COB}, \mathrm{Carlos}$ Arthur Nuzman afirmou que "O legado das Olimpíadas será maior que o do Pan 2007, até porque a ODEPA não exige legado". Conforme Rádio CBN, 09 de março de 2010. 
- SOBRE AS SUGESTÕES DOS RESPONDENTES

Pedimos aos respondentes que sugerissem as necessidades para a realização destes megaeventos com qualidade. As palavras que mais apareceram nesta ordem foram:

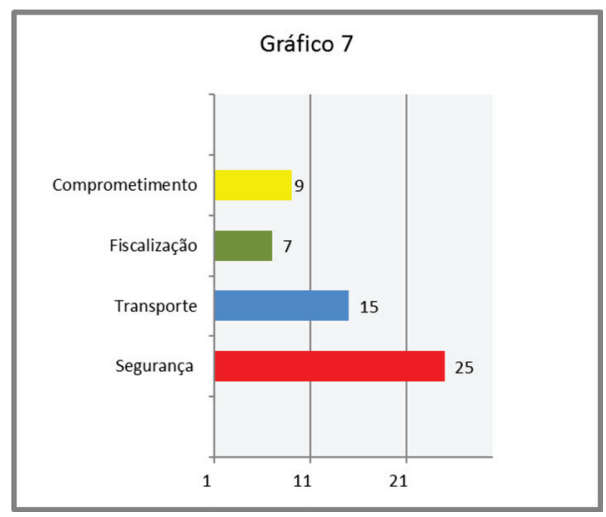

Acreditamos que este dado talvez reflita a percepção da população da cidade do Rio de Janeiro como um todo. ${ }^{4}$ Segurança e transporte foram as palavras mais citadas em nosso estudo, seguidas de comprometimento e fiscalização.

A palavra segurança foi citada 24 vezes de forma espontânea. Um respondente escreveu inclusive que as melhorias em segurança deveriam ser permanentes e não apenas durante a realização destes megaeventos. Tal fato nos fez recordar do aparato de segurança feito durante a ECO $92^{5}$ e o Pan-Americano de 2007 na cidade do Rio de Janeiro. $O$ grande aporte das unidades de segurança para a garantia da ordem na realização destes eventos acaba por ter um efeito de uma maior sensação de segurança.

Quanto à palavra transporte, tivemos 14 ocorrências. Acreditamos que este número pode estar relacionado ao fato da mídia pautar as futuras realizações em termos de desenvolvimento de uma nova malha viária e a melhoria da existente. ${ }^{6}$ A ênfase é sobre a necessidade dos deslocamentos das delegações do aeroporto para os locais de estadia e competição, e com isso toda a população desfrutaria da infraestrutura construída.

4. Conforme pesquisa Veja Rio/Instituto Brasileiro de Pesquisa Social, em 665 dos entrevistados consideram a violência e a falta de segurança como os maiores problemas a serem enfrentados. Veja, n 9, 3 de mar. 2010.

5. Conferência das Nações Unidas para o Meio ambiente e Desenvolvimento (CNUMAD) realizada na cidade do Rio de Janeiro entre 03 a 14 de junho de 1992.

6. As propostas governamentais nas esferas federal, estadual e municipal prevêem desde a implementação dos Veículos Leves sobre Trilhos (VLTs) passando pelas vias expressas para ônibus (BRT, sigla em inglês para Bus Rapid Transit) e até mesmo a expansão do número de estações de metrô. Conforme jornal O Globo, 10 de agosto de 2009. 
A palavra comprometimento obteve 9 ocorrências. Inferimos que o comprometimento aqui se relaciona às esferas políticas responsáveis pela realização destes megaeventos no Brasil.

Por último, mas não menos importante, obtivemos a palavra fiscalização, com 7 ocorrências. Como escrevemos no início de nossa pesquisa, há uma preocupação com a gerência dos recursos públicos a serem usados nestes dois megaeventos, pois ainda circulam notícias sobre o mau uso de verbas públicas para o Pan-Americano Rio 2007.

Somadas, estas duas últimas ocorrências representam mais citações do que a palavra transporte. A qualidade na gestão e posterior avaliação das tomadas de decisão é uma constante para diversos autores (MASCARENHAS, 2008; PREUSS, 2008; TRUÑO, 2008). Inferimos que os estudos sobre o investimento financeiro nestes megaeventos levantam a possibilidade de não haver accountability por parte dos gestores desses recursos e que outras denúncias de má gestão aconteçam ao longo deste período. ${ }^{7}$

\section{CONSIDERAÇÕES FINAIS}

Ao longo da pesquisa problematizamos a percepção destes dois megaeventos esportivos para os profissionais de educação física que atuam em espaços públicos de educação dentro da cidade do Rio de Janeiro. Sabemos que a população de nosso estudo é específica e sensível às políticas públicas voltadas ao esporte, principalmente aquele praticado nas escolas públicas.

Com a aproximação temporal destes megaeventos, o aumento das intervenções urbanas e a circulação na mídia de notícias sobre a Copa do Mundo FIFA 2014 e das Olimpíadas Rio 2016 poderemos ter resultados distintos, visto que é preciso estudar este grupo aplicando-lhe novos questionários ao longo dos anos, sobretudo durante e depois destes megaeventos. Além disso, é necessário pensar estes eventos de forma a integrar os profissionais de educação física que atuam nas escolas e nas instituições esportivas públicas da cidade do Rio de Janeiro nas diversas esferas governamentais, dando-lhes a oportunidade de desenvolver seu trabalho com qualidade e segurança junto às crianças, adolescentes e adultos, quer seja na massificação da iniciação esportiva, quer seja até mesmo com a possibilidade de descoberta futuros talentos.

A longo prazo, a educação física e seus profissionais que atuam na esfera pública, quer seja em escolas, quer seja em espaços públicos esportivos, tem um

7. Palavras correspondentes em português seriam transparência, confiabilidade e responsabilidade. 
compromisso com a propagação de uma educação olímpica que esteja voltada para o respeito à diferença, ao desenvolvimento de condutas democráticas, à tolerância e ao multiculturalismo. Talvez para nós seja esta seja a grande oportunidade (RUBIO, 2009).

Estudos futuros podem suscitar discussões sobre o legado destes megaeventos para profissionais de educação física residentes em outros estados e cidades. Também seria importante investigar outros grupos de professores com atuações diferenciadas da população aqui estudada, tais como aqueles que estão envolvidos nas esferas políticas, no alto rendimento, nas organizações esportivas e no meio acadêmico.

Os megaeventos são compreendidos como uma fonte mobilizadora para atração de investimentos e os custos de oportunidade não devem ser desconsiderados. A pergunta feita por Madruga (2008, p. 6I) é significativa: “... caso não houvesse os Jogos Olímpicos de 2016 no Rio de Janeiro, esses estimados investimentos de 10 bilhões de dólares iriam para a infraestrutura da cidade candidata?".

Seria importante se as intervenções urbanísticas fossem pensadas e feitas ao longo do tempo, em benefício primário para os moradores e pagadores de impostos destas cidades e regiões. $\bigcirc$ problema aqui que apontamos é que a população se torna beneficiária de segundo plano do tal legado, isto é, as intervenções necessárias serão ou não realizadas basicamente em função da passagem destes megaeventos no Brasil.

\section{Legacies of Mega Events in Brazil: the Cases of 2014 FIFA World Cup and RIO 2016}

ABSTRACT: Brazil is about to host two of the most important world sport events, the FIFA World Cup 2014 and the Olympic Games Rio 2016. The purpose of this research is to observe the perceptions of physical education professionals from Rio de Janeiro in regard to the legacy these mega events may bring to their lives in terms of professional development as well as in questions related to their routine. In our discussion about the results we raise topics about the impact and expectations of these mega events in the job market to these teachers, professional valorization, practice, and raise interest in sport, social legacy and suggestions to the success of these events.

KEYWORDS: Legacies; 2014 Fifa World Cup; Rio de Janeiro 2016 Olympic Games; Perception.

Percepción sobre el legado de los grandes eventos deportivos en Brasil: el caso del Campeonato Mundial de Fútbol FIFA 2012 y los Juegos Olímpicos RIO 2016

RESUMEN: Brasil será sede de los dos más importantes eventos deportivos del mundo, la Copa del Mundo de la FIFA 2014 y los Juegos Olímpicos Rio 2016. El objetivo de esta investigación es 
verificar la percepción de los profesionales de Educación Física de la ciudad de Río de Janeiro sobre el resultado que estos mega eventos pueden traer para sus vidas, tanto en términos de desarrollo profesional como en cuestiones relacionadas a su vida cotidiana. En nuestros resultados levantamos puntos sobre los impactos e expectativas sobre los mega eventos en el mercado de trabajo para estos profesionales, valorización profesional, práctica e aumentos de interés deportivo, resultado social y sus sugerencias para el éxito de estos eventos. PALABRAS-CLAVE: Legados desportivos; Campeonato Mundial de Fútbol FIFA 20 / 4; Juegos Olímpicos RIO 20 l6; percepción.

\section{REFERÊNCIAS}

BECHARA, M. Modelo M4 para a gestão de legados de megaeventos esportivos com foco na responsabilidade social e políticas públicas. In: DACOSTA, L.; CORREA, D.; RIZUTTI, E.; VILLANO, B.; MIRAGAYA, A. Eds. Legados de megaeventos esportivos. Brasília: Ministério do Esporte, 2008. pp. 249- 263.

BETTI, M. Copa do Mundo e Jogos Olímpicos: inversionalidade e transversalidades na cultura esportivae na Educação Física escolar. Motrivivência, Santa Catarina, Ano XXI, n 32/33. Jun-Dez./2009. Disponível em: http://www.rbceonline.org.br/revista/index.php/RBCE/issue/ view/I29/showToc. Acesso em: 15 de janeiro de 2012.

CARVALHO, L.; MELO, A.; \& DACOSTA, L. Percepção dos profissionais de educação física do Rio de Janeiro e Espírito Santo sobre impactos dos Jogos Pan-Americanos Rio 2007. In: DACOSTA, L.; CORREAA, D.; RIZUTTI, E.; VILLANO, B.; MIRAGAYA, A. Eds. Legados de megaeventos esportivos. Brasília: Ministério do Esporte, 2008. pp. 309- 315.

CAVALLI, A.; CAVALLI, M.; MESQUITA, R. Impacto dos jogos Pan-Americanos Rio 2007: percepção de acadêmicos de educação física da FEFID/PUCRS- Porto Alegre. In: DACOSTA, L.; CORRÊA, D.; RIZUTTI, E.; VILLANO, B.; MIRAGAYA, A. Eds. Legados de megaeventos esportivos. Brasília: Ministério do Esporte, 2008. pp. 293-301.

DACOSTA, L.; CORRÊA, D.; RIZUTTI, E.; VILLANO, B.; MIRAGAYA, A. Eds. Legados de megaeventos esportivos. Brasília: Ministério do Esporte, 2008.

DACOSTA,L., MIRAGAYA, A. Estado da arte do conhecimento sobre legados de megaeventos esportivos no exterior e no Brasil - Introdução aos temas e autores deste livro. In: DACOSTA, L.; CORREAA, D.; RIZUTTI, E.; VILLANO, B.; MIRAGAYA, A. Eds. Legados de megaeventos esportivos. Brasília: Ministério do Esporte, 2008. pp. 33- 45.

FERREIRA, N.; COSTA, V. Legado político dos Jogos Pan-Americanos do Rio de Janeiro: O imaginário do Pan. In: DACOSTA, L.; CORREAA, D.; RIZUTTI, E.; VILLANO, B.; MIRAGAYA, A. Eds. Legados de megaeventos esportivos. Brasília: Ministério do Esporte, 2008. pp. 27I - 283.

FOUCAULT, M. A ordem do discurso. A ordem do discurso. São Paulo: Loyola, 1996. 
GNECCO, J. Apontamentos sobre a realização os legados dos Jogos Pan-Americanos Rio 2007. In: DACOSTA, L.; CORREAA, D.; RIZUTTI, E.; VILLANO, B.; MIRAGAYA, A. Eds. Legados de megaeventos esportivos. Brasília: Ministério do Esporte, 2008. pp. 265- 270.

GURGEL, A. O papel da mídia na construção do legado dos Jogos Pan-Americanos Rio 2007: Análise Pós-evento. In: DACOSTA, L.; CORRÊA, D.; RIZUTTI, E.; VILLANO, B.; MIRAGAYA, A. Eds. Legados de megaeventos esportivos. Brasília: Ministério do Esporte, 2008. pp. 489- 492.

HAAS, A.; DIAS, C.; ROLIM.; L.; TODT, N. Cerimônia de abertura dos jogos Pan-Americanos 2007: uma avaliação a partir dos parâmetros olímpicos. In: DACOSTA, L.; CORREAA, D.; RIZUTTI, E.; VILLANO, B.; MIRAGAYA, A. Eds. Legados de megaeventos esportivos. Brasília: Ministério do Esporte, 2008. pp. 317-329.

LOVISOLO, H.; LUCERO, F. Educação física escolar: esporte, competição e talento. Lecturas: Educación física y deportes. n 92. 2006.

MADRUGA, D. Megaeventos esportivos como gestão de custos de oportunidade. In: DACOSTA, L.; CORREAA, D.; RIZUTTI, E.; VILLANO, B.; MIRAGAYA, A. Eds. Legados de megaeventos esportivos. Brasília: Ministério do Esporte, 2008. pp. 59- 63.

MASCARENHAS, G. Barcelona - 1992: um modelo em questão. In: DACOSTA, L.; CORREAA, D.; RIZUTTI, E.; VILLANO, B.; MIRAGAYA, A. Eds. Legados de megaeventos esportivos. Brasília: Ministério do Esporte, 2008. pp. 189- 193.

MATARUNA, L. Percepção dos Jogos Pan-americanos Rio 2007 por especialistas internacionais em Estudos Olímpicos. In: DACOSTA, L.; CORREAA, D.; RIZUTTI, E.; VILLANO, B.; MIRAGAYA, A. Eds. Legados de megaeventos esportivos. Brasília: Ministério do Esporte, 2008. pp. 337- 342 .

MAZO, J. "Universíade de 63": qual o legado para a cidade de Porto Alegre. In: DACOSTA, L.; CORREAA, D.; RIZUTTI, E.; VILLANO, B.; MIRAGAYA, A. Eds. Legados de megaeventos esportivos. Brasília: Ministério do Esporte, 2008. pp. 429- 430.

MEZZAROBA, C.; PIRES, P. Os jogos Pan-Americanos Rio 2007 e o agendamento midiático-esportivo: um estudo de recepção co escolares. Revista Brasileira de Ciências do Esporte. Florianópolis, v. 33, n. 2, p. 337-355, abr./jun. 20। I. Disponível em: <http://www.rbceonline.org. br/revista/index.php/RBCE/Issue/view/I29/showToc>. Acesso em: 02 de fevereiro de 2012.

MOTRIVIVÊNCIA. Dossiê 2007-2016 - A década dos megaeventos no Brasil. Ano XXI, n 32/33. Jun-Dez./2009.

MOURÃO, L.; VIANNA, A.; MOURA, D.; LUZIA, M. Útil e agradável? Um diagnóstico da percepção de acadêmicos da educação física sobre os Jogos Pan-americanos e sua adesão ao voluntariado. In: DACOSTA, L.; CORRÊA, D.; RIZUTTI, E.; VILLANO, B.; MIRAGAYA, A. Eds. Legados de megaeventos esportivos. Brasília: Ministério do Esporte, 2008. pp. 285- 292. 
PIRES, Giovani de Lorenzi Pires. A educação física e o discurso midiático: abordagem crítico-emancipatória em pesquisa-ação no ensino de graduação. Subsídios para a saúde? Campinas, Universidade Estadual de Campinas, 2.000, 25 I p. Tese (doutorado em Educação Física), Faculdade de Educação Física, Unicamp.

POYTER, G. Regeneração urbana e legado olímpico de Londres 20 I 2. In: DACOSTA, L.; CORREAA, D.; RIZUTTI, E.; VILLANO, B.; MIRAGAYA, A. Eds. Legados de megaeventos esportivos. Brasília: Ministério do Esporte, 2008. pp. |2| - |5 |.

PREUSS, H. Impacto econômicos de megaeventos: copa do mudo de futebol e jogos olímpicos. In: DACOSTA, L.; CORREAA, D.; RIZUTTI, E.; VILLANO, B.; MIRAGAYA, A. Eds. Legados de megaeventos esportivos. Brasília: Ministério do Esporte, 2008. pp. 79- 101.

PRONI, M. Observações sobre os impactos econômicos esperados dos jogos olímpicos de 2016 . Motrivivência, Santa Catarina, Ano XXI, no 32/33. Jun-Dez./2009. Disponível em: http://www.rbceonline.org.br/revista/index.php/RBCE/Issue/view/I 29/showToc. Acesso em: 30 de janeiro de 2012.

RAEDER, S. Desenvolvimento urbano em sedes de Megaeventos Esportivos. In: DACOSTA, L.; CORREAA, D.; RIZUTTI, E.; VILLANO, B.; MIRAGAYA, A. Eds. Legados de megaeventos esportivos. Brasília: Ministério do Esporte, 2008. pp. 200- 209.

RUBIO, K. O legado educativo dos megaeventos esportivos. Motrivivência, Santa Catarina, Ano XXI, no 32/33. Jun-Dez./2009. Disponível em: http://www.rbceonline.org.br/revista/ index.php/RBCE/issue/view/I29/showToc. Acesso em: 01 de fevereiro de 2012.

RIBEIRO, C.; DIMEO, P.'I am not a foreigner anymore' a micro-sociological study of experiences of Brazilian futsal players in European leagues. Movimento. vol. I 5. n. 2. p.33- 44. 2009.

SOUSA, F; SILVA, A. Os jogos Pan-Americanos na percepção dos discentes do Curso de Educação Física na Cidade de Fortaleza. In: DACOSTA, L.; CORRÊA, D.; RIZUTTI, E.; VILLANO, B.; MIRAGAYA, A. Eds. Legados de megaeventos esportivos. Brasília: Ministério do Esporte, 2008. pp. 303- 307.

TAVARES, O. Educação olímpica no Rio de Janeiro: notas iniciais para o desenvolvimento de um modelo. In: DACOSTA, L.; CORREAA, D.; RIZUTTI, E.; VILLANO, B.; MIRAGAYA, A. Eds. Legados de megaeventos esportivos. Brasília: Ministério do Esporte, 2008. pp. 343- 355.

TURINI, M.; SANTOS, J. Promoção de fair play nos jogos estudantis de Duque de Caxias - RJ através do uso da internet: um exemplo de educação olímpica para a cidade do Rio de Janeiro. In: DACOSTA, L.; CORREAA, D.; RIZUTTI, E.; VILLANO, B.; MIRAGAYA, A. Eds. Legados de megaeventos esportivos. Brasília: Ministério do Esporte, 2008. pp. 367- 375.

THOMAS, J.; NELSON, J. SILVERMAN, S. Métodos de pesquisa em atividade física. Porto Alegre: Artmed, 2007. 
TRIVIÑOS, A. Pesquisas em ciências sociais: São Paulo. Atlas, 1993.

TRUÑO, E. Estruturação de megaeventos e regeneração urbana: Barcelona 1992 e Torino 2006. In: DACOSTA, L.; CORREAA, D.; RIZUTTII, E.; VILLANO, B.; MIRAGAYA, A. Eds. Legados de megaeventos esportivos. Brasília: Ministério do Esporte, 2008. pp. 167- 173.

Recebido em: 25 ago. 201 I Aprovado em: 30 dez. 2011

Endereço para correspondência: Carlos Henrique de Vasconcellos Ribeiro Rua João Pessoa, I53, apt: I 102

Icaraí Niterói, RJ CEP: $24220-330$ 